\title{
The Role Of Computer In Library Management
}

\author{
Xiuli $\mathrm{LI}^{1, \mathrm{a}^{*}} \quad$ Feng Zheng ${ }^{2, \mathrm{~b}}$ \\ ${ }^{1} 1666$ \# in Karen Lake Street of nine economic development zone, Chang Chun of Ji lin, in China \\ ${ }^{2} 1666$ \# in Karen Lake Street of nine economic development zone, Chang Chun of $\mathrm{Ji}$ lin, in China \\ a lixiulibb@126.com, b422126561@qq.com,
}

\section{Keywords: Computer; Library management; Information technology}

Abstract. With the continuous development of science and technology, information technology is facing the development of various fields. As the main carrier of the social and economic 1P technology and culture information, Library management provides the development space for computer technology and network technology. The introduction of computer network technology in the library management to the current library management of the organizational form of the upgrade has a very good role in promoting.

In today's information technology continues to progress, the library should take the opportunity to seize the whole face lifting of computer technology in the management of the construction of the library, the establishment of a computer network management system, in order to meet the overall needs of high quality library in the network era. The computer plays an important role in the management of library, the computer management system the perfect help to speed up the modernization of Library management.

\section{The role of computer in the library catalog}

As an important part of library work, cataloging work has been the focus and difficulty of library work, directly determines whether the reader smoothly to find books retrieval books. Standardization, convenience and accuracy are the basic requirements of the library cataloging work. Cataloging work can not only improve the convenience of the reader of books retrieval and reading, but also have a good role to share for the library resources. The data collection in computer catalogue can be used to search or browse. Retrieval method is to obtain the content of the literature and the identification of the system. The browsing method is to organize and collect the data of the questionnaire of the library and store it in the computer network, and establish a new content, high density, network of data system. To establish a library network system from the perspective of comprehensive survey, access to sufficient data, in order to better manage the information and data in the library.

Library cataloging work is a process of describing and recording all kinds of documents in the library according to certain rules. As one of the core of the work of the library, the library cataloging work in our country has been standardized and programmed since 1998, because the catalogue database is too large, the consistency and uniqueness of the catalogue can not be guaranteed. Therefore, the standardization of Library Cataloging needs reform and innovation in order to meet the requirements of modern library. Library Cataloging to closer to international, adhere to its own characteristics, to the integration of resources from the direction of pure traditional cataloging. To actively introduce advanced international cataloguing rules, make full use of the advantages of computer cataloguing, the library cataloging in China with international 
standards. In the continuous development of global information resources sharing and expansion driven under, the our country library including public library and university library should strengthen library management of network resource sharing consciousness and Library's social consciousness, to establish service-oriented philosophy, will read placed in a central location, reflection of book cataloguing work in the place of the reader, with practicality as the main purpose, the center of the cataloging work of the library in to meet the needs of users.

\section{The role of computer in the library network security}

(a) the unsafe factors of Library network. Many colleges and universities, as well as the unit of the library network problem does not get enough attention, the management of the computer in the library, and ignored the importance of network security issues. Due to the lax slack of the network security management, the hacker's invasion of the library computer system caused the loss of data. In addition, many libraries in the network maintenance personnel are not professional, have not received formal training, and even a lot of work study program of the students such a newbie served as a network security maintenance in the current, which is a very important work, which is very large risks in network security. The current library network software development there are a variety of vulnerabilities, hackers may use these vulnerabilities to attack the library network system and cause network paralysis. Computer viruses have very big threat to the library network, often a computer poisoning will be propagated to all computer through the network, the network system problems. And some of the library network administrators usually focus placed on the student account and log system review, not often for computer network system safety maintenance, makes the library network security, there is a considerable risk.

(b) Computer Security Technologies for library network security protection. There are all kinds of security risks in the network security of the library at present. Therefore, it is supposed to increase the use of computer security technology, protect the security of library network, and ensure the normal operation of library management. A computer virus is a major threat to the network security of the library, library network administrators cope with virus prevention and treatment have perfect understanding and grasp and potent anti-virus software installed in the library network host, intensify the prevention and control of the virus, set the network firewall, virus shut out. At the same time to update anti-virus software regularly to update the virus database, but also the important data server to make a special protection, the prevention and control of the work of the virus in an important position. In order to prevent the intrusion of illegal users, the library should encrypt the information. Information encryption, as one of the widely used computer security technologies, has the function of protecting network information from being compromised. At the same time, the information encryption can also avoid the malicious software, the network caused by the burden is very small. Usually, information encryption can be classified as link encryption, power-off encryption and node encryption in three ways, the three have their own characteristics and advantages, the library network administrator to choose the most suitable network information encryption technology according to library network has its own characteristics. Maintaining network security should also introduce authentication technology, identity authentication technology in the field of network security has a very common application, library network security is very suitable for the use of this technology. Library network management also should pay attention to the use of intrusion detection technology. The intrusion detection technology now can analyze key areas of information in a computer network by collecting, on whether the network is under attack and attack damage to detect and judge. When the system is found signs of an attack, 
the system will automatically open network real-time protection, and repair of attack damage, in violation of the invasion by again before active interception. Intrusion detection technology combined with firewall technology can effectively prevent network intrusion, the establishment of a network of multi-layer defense.

\section{Conclusion}

In short, the computer and network technology in library management has a very important position, the application of computer technology in the management of library is the inevitable trend of the management of the library in the future development. It can not only expand the library services, they can bring benefits for the library. In the library development has a great role in promoting.

\section{Reference:}

[1]Yuhua Yang. Computer network and library management[J]. computer CD software and applications, 2012 (06): 135-136.

[2]Dongmei Wang. Application of computer security technology and protection measures in library management [J]. intelligence, 2012 (07): 73-74.

[3]Meiyan Qu. Experience in Computer Cataloging in library management in the [J]. Folk Art and Literature 2013 (04): 47-47. 